\title{
A systematic review and meta-analysis of effect of vitamin D levels on the incidence of COVID-19
}

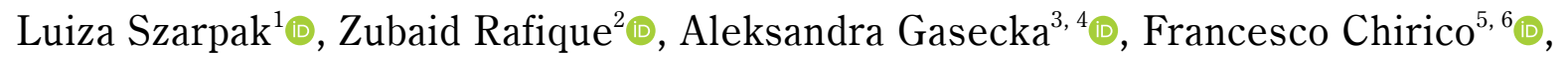

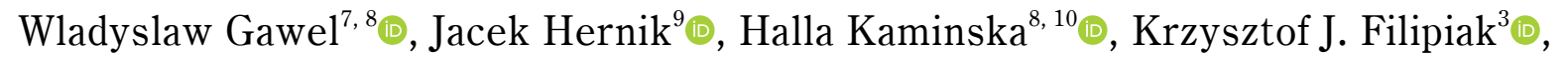 \\ Milosz J. Jaguszewski1 ${ }^{11}$, Lukasz Szarpak ${ }^{9,12}$ (1)
}

${ }^{1}$ Institute of Outcomes Research, Polonia University, Czestochowa, Poland

${ }^{2}$ Henry JN Taub Department of Emergency Medicine, Baylor College of Medicine, Houston, TX, United States

${ }^{3} 1^{\text {st }}$ Chair and Department of Cardiology, Medical University of Warsaw, Poland

${ }^{4}$ Department of Cardiology, University Medical Center Utrecht, The Netherlands

${ }^{5}$ Post-graduate School of Occupational Health, Università Cattolica del Sacro Cuore, Rome, Italy

${ }^{6}$ Health Service Department, Italian State Police, Ministry of the Interior, Milano, Italy

${ }^{7}$ Department of Surgery, The Silesian Hospital in Opava, Czech Republic

${ }^{8}$ Polish Society of Disaster Medicine, Warsaw, Poland

${ }^{9}$ Maria Sklodowska-Curie Medical Academy, Warsaw, Poland

${ }^{10}$ Department of Pediatrics and Children's Diabetology, Faculty of Medical Sciences in Katowice,

Medical University of Silesia, Zabrze, Poland

${ }^{11} 1^{\text {st }}$ Department of Cardiology, Medical University of Gdansk, Poland

${ }^{12}$ Maria Sklodowska-Curie Bialystok Oncology Center, Bialystok, Poland

\section{This paper was guest edited by Prof. Togay Evrin}

\begin{abstract}
Background: Coronavirus disease 2019 (COVID-19) is a disease primarily affecting the respiratory tract, however due to the nature of the pathogenesis it is able to affect the whole body. So far, no causative treatment has been found and the main strategy when dealing with COVID-19 relies on widespread vaccination programs and symptomatic treatment. Vitamin D due to its ability to modulate the immunological system has been proposed as a factor playing role in the organism response to the severe acute respiratory syndrome coronavirus 2 (SARS-CoV-2) infection. Therefore, we decided to perform this meta-analysis which aimed to establish a connection between vitamin D status and COVID-19 infection.

Methods: Study was designed as a systematic review and meta-analysis. PubMed, EMBASE, Web of Science, Cochrane Collaboration Databases and Scopus electronic databases were searched for relevant studies from database inception to May 10 $0^{\text {th }}$ 2021. Mean differences (MDs) with their 95\% confidence intervals (CI) were calculated.

Results: Thirteen studies providing data for 14,485 participants met the inclusion criteria. Mean vitamin D levels in SARS-CoV-2 negative patients was $17.7 \pm 6.9 \mathrm{ng} / \mathrm{mL}$ compared to SARS-CoV-2 positive patients $14.1 \pm 8.2 \mathrm{ng} / \mathrm{mL}\left(M D=3.93 ; 95 \%\right.$ CI 2.84-5.02; $\left.I^{2}=99 \% ; p<0.001\right)$.

Conclusions: Low serum vitamin D levels are statistically significantly associated with the risk of COVID-19 infection. Supplementation of vitamin D especially in the deficiency risk groups is indicated. (Cardiol J 2021; 28, 5: 647-654)
\end{abstract}

Key words: vitamin D, COVID-19, coronavirus disease 2019, SARS-CoV-2, systematic review, meta-analysis

Address for correspondence: Lukasz Szarpak, Assoc. Prof. PhD, DPH, MBA, Maria Sklodowska-Curie Medical Academy in Warsaw, Al. Solidarności 12, 03-411 Warszawa, Poland, tel: +48 500186 225, e-mail: lukasz.szarpak@gmail.com

Received: 30.05.2021 Accepted: 4.06.2021 Early publication date: 2.07.2021

This article is available in open access under Creative Common Attribution-Non-Commercial-No Derivatives 4.0 International (CC BY-NC-ND 4.0) license, allowing to download articles and share them with others as long as they credit the authors and the publisher, but without permission to change them in any way or use them commercially. 


\section{Introduction}

Since the outbreak of the new type of coronavirus disease called novel coronavirus disease 2019 (COVID-19) in Wuhan China in 2019 [1, 2] medical systems all over the world have been under immense pressure, resulting in a rapid increase in the cost of care [3]. The virus infects the host via angiotensin converting enzyme 2 (ACE2) [4]. Due to the fact that ACE2 expression is the highest in the respiratory tract [5] it is the respiratory symptoms that are most prominent in COVID-19, however the ACE2 is expressed in the whole body which explains the multisymptomatic nature of the disease [6]. Due to rapidly spreading nature of the disease and its ability to disorganize the healthcare systems by the increased number of patients requiring intensive care the research was focused on finding a causative treatment. Several drugs have been proposed which include, but are not limited to: hydroxychloroquine $[7,8]$, janus kinase 2 inhibitor Fedratinib [9] or Remdesmivir [10]. None of which had been able to demonstrate utility in the treatment of COVID-19. Therefore, the efforts were focused on the development of the vaccines and so far, there are several drugs on the market that are able to relieve some of the tension placed on the healthcare system by COVID-19 [11, 12]. However, while vaccination programs are widespread and the number of vaccinated patients grows, the underlying risk factors for the severe course of COVID-19 are still being investigated. So far, several factors were established i.e.: obesity [13], diabetes [14] and smoking [15]. The common denominator for all of these risk factors is the disturbed immunological response which may in fact be the underlying mechanism for the severe course of COVID-19. One of the most common and thoroughly examined causes of immunosuppression is vitamin D deficiency [16]. Vitamin D plays a key role the modulation of the immunological response in both autoimmune and infectious diseases [17], via multiple patterns. Among many others it modulates the maturation of macrophages [18], regulates the T-lymphocyte stimulatory function of antigen-presenting cells [19] and regulates B-lymphocyte proliferation [18]. Therefore, it comes as no surprise that in the era of COVID-19, vitamin D became an object of interest for much research worldwide in terms of preventing the severe course of the disease. We decided to perform this meta-analysis in order to establish a possible link between the levels of vitamin $\mathrm{D}$ and COVID-19 infections.

\section{Methods}

This trial was prepared following the recommendations of the Preferred Reporting Items for Systematic Review and Meta-Analysis (PRISMA) guidelines [19]. Before commencing the study, analyses methods as well as inclusion and exclusion criteria to be used were agreed upon. Because of the nature of this systematic review and metaanalysis, this study was exempt review by the institutional review board.

\section{Literature search}

A systematic review was carried out using PubMed, EMBASE, Web of Science, Cochrane Collaboration Databases and Scopus electronic databases. The most recent search was performed on May $10^{\text {th }}, 2021$. Titles and abstracts were screened by two authors independently (A.G. and W.G.). All retrieved articles were reviewed by two authors (J.S. and A.G.). Any disagreement was resolved through consensus or, if necessary, by discussion with a third author (L.S.).

The search was performed using the following terms: "25-hydroxyvitamin D" OR " $25(\mathrm{OH}) \mathrm{D}$ ” OR "vitamin D” AND "coronavirus" OR "SARS-CoV-2" OR “COVID-19”. A manual search of references listed in reviews and reports was also performed. Only full articles in the English language were considered. All references were saved in an EndNote (End Note, Inc, Philadelphia, PA) library used to identify duplicates.

\section{Inclusion and exclusion criteria}

Studies included in this meta-analysis met the following PICOS criteria: (1) PARTICIPANTS; patients > 18 years of age, (2) INTERVENTION; SARS-CoV-2 positive patients, (3) COMPARISON; SARS-CoV-2 negative patients, (4) OUTCOMES; detailed information for vitamin D-3 levels, (5) STUDY DESIGN; randomized controlled trials, quasi-randomized or observational studies comparing cardiac arrest during and before the COVID-19 period for their effects in patients with cardiac arrest. Reviews, simulation trials, animal studies, letters, conference papers and case studies were excluded.

\section{Data extraction}

Two reviewers (L.S. and W.G.) independently assessed each article to determine which article met the inclusion criteria. Any disagreements were resolved by consensus with a third reviewer (A.G.). The following information was extracted from each included study: the first author's name, 
year of publication, study design, country, sample size, age, gender, vitamin D level in SARS-CoV-2 positive and negative patients.

\section{Quality assessment}

Two reviewers (A.G. and H.K.) independently extracted individual study data and evaluated studies for risk of bias. Any disagreements were discussed and resolved in a consensus meeting with the third reviewer (M.M.). The revised tool for risk of bias in randomized trials - RoB 2 tool was used to assess the quality of randomized studies [20]. Moreover, the Robvis application was used to visualize risk of bias assessments [21].

The evaluation consisted of the following domains: confounding, participant selection, classification of interventions, deviation from interventions, missing data, outcome measurement and selection of reported results. Each domain was assessed according to the following scale: serious, moderate and low.

\section{Statistical analysis}

All statistical analysis were performed using RevMan v.5.4 (The Cochrane Collaboration, Oxford, Copenhagen, Denmark) and STATA v.16.1. (StataCorp LLC, Texas, USA). All tests were 2-sided and a $p$ value of less than 0.05 was considered as statistically significant. To analyze dichotomous outcomes the Mantel-Haenszel method was used, and results are reported as odds ratios with a 95\% confidence interval (CI) and two tailed $\mathrm{p}$ values. The inverse variance model with a $95 \%$ CI was used to analyze continuous outcome differences and data are reported as the mean difference (MD). Results are presented as risk ratios with $95 \%$ CI for dichotomous measures. When the continuous data were reported in the articles as the median and interquartile range, estimated means and standard deviations were calculated using the formula described by Hozo et al. [22].

Data heterogeneity was assessed using the tau-squared and I-squared statistics. Heterogeneity

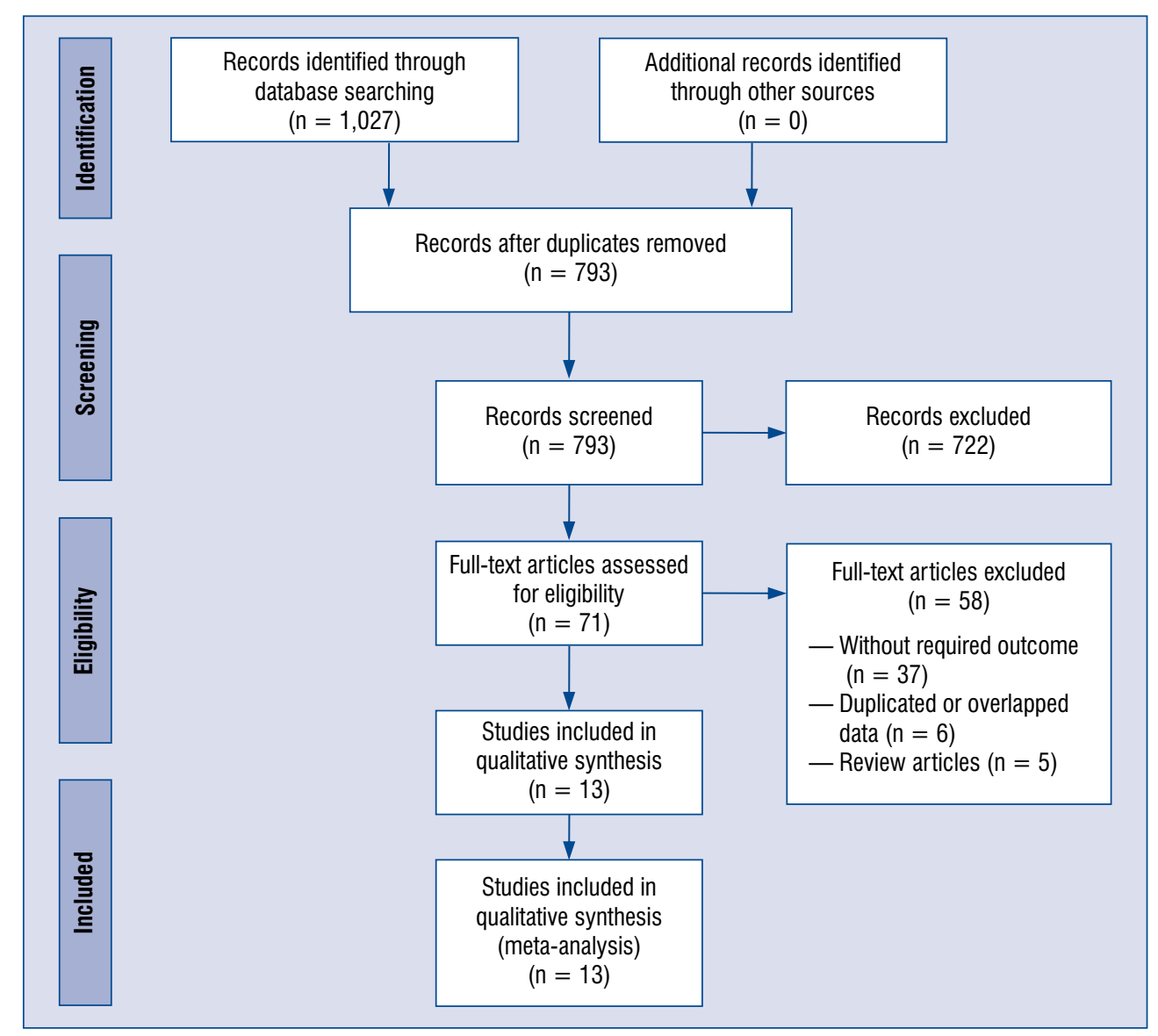

Figure 1. Flow diagram showing stages of the database search and study selection as per Preferred Reporting Items for Systematic reviews and Meta-analysis (PRISMA) guideline. 
was detected with the chi-squared test with $n-1$ degrees of freedom, which was expressed as $\mathrm{I}^{2}$ [23]. For all analysis a random model was used.

\section{Results}

\section{Characteristics of studies included in the meta-analysis}

A detailed description of the process of study selection was presented in Figure 1. We found 1,027 potential citations during the search of databases. 234 articles were excluded because they were duplicates, and 722 articles were also excluded because they were unrelated studies. The remaining 71 articles were fully reviewed, and 13 studies providing data for 14,485 participants met the inclusion criteria and were included in the current meta-analysis [24-36]. The details of selected trials are summarized in Table 1. Of those trials, 3 studies were performed in United Kingdom, 2 studies in Iran, 2 in Saudi Arabia, 2 in Italy, and 1 in each of the following countries: Spain, Republic of Korea, Israel and China.

\section{Result of the meta-analysis}

Polled analysis of all 13 studies reported vitamin $\mathrm{D}$ levels in the severe acute respiratory syndrome coronavirus 2 (SARS-CoV-2) negative versus positive patients is shown in Figure 2. Mean vitamin D levels in SARS-CoV-2 negative patients was $17.7 \pm 6.9 \mathrm{ng} / \mathrm{mL}$ compared to SARS-CoV-2 positive patients $14.1 \pm 8.2 \mathrm{ng} / \mathrm{mL}(\mathrm{MD}=3.93$; 95\% CI 2.84-5.02; $\mathrm{I}^{2}=99 \%$; $\left.<0.001\right)$.

The detailed risk of bias abuts the methodological quality of the included studies that are elaborated and summarized in Figures 3 and 4.

\section{Discussion}

The number of reports indicating the potential role of vitamin D deficiency in the COVID-19 increases [37]. The potential role in the prevention of a severe course of COVID-19 was further strengthened by the identification of calcitriol (active form of vitamin D) as the regulator of renin-angiotensin system (RAS), of which an overactivation is associated with poor prognosis [38, 39]. Abdollahi et al. [24] found that patients who suffer from vitamin D deficiency are more vulnerable to COVID-19 infection. However, he underlines that the patients suffering from COVID-19 were more likely to be overweight or obese, while obesity is an independent risk factor for a more severe course of the disease [40] it must be noted that patients who are

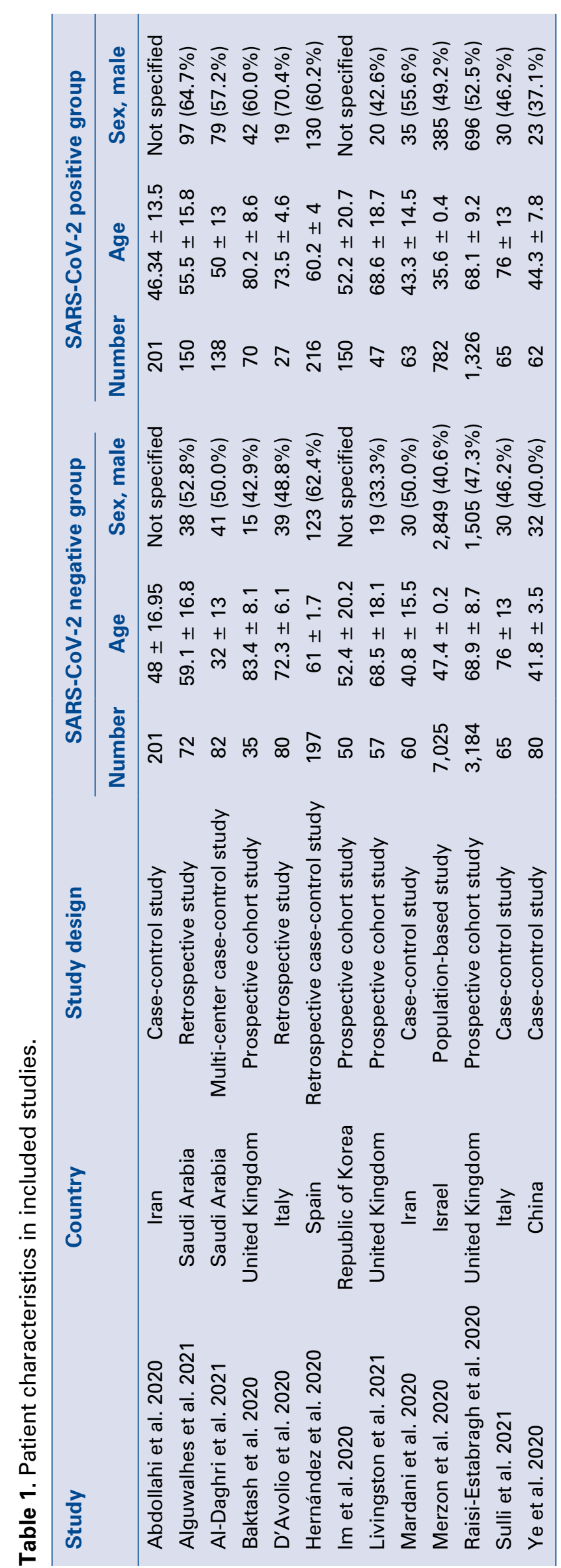




\begin{tabular}{|c|c|c|c|c|c|c|c|c|c|c|c|c|}
\hline \multirow{3}{*}{$\begin{array}{l}\text { Study or Subgroup } \\
\text { Abdollahi } 2020 \text { [24] }\end{array}$} & \multicolumn{3}{|c|}{ SARS-CoV-2 (-) } & \multicolumn{3}{|c|}{ SARS-CoV-2 (+) } & \multirow[b]{2}{*}{ Weight } & \multirow{3}{*}{$\begin{array}{c}\text { Mean Difference } \\
\text { IV, Random, 95\% CI } \\
-3.00[-3.40,-2.60]\end{array}$} & \multirow{2}{*}{\multicolumn{4}{|c|}{$\begin{array}{c}\text { Mean Difference } \\
\text { IV, Random, } 95 \% \mathrm{CI}\end{array}$}} \\
\hline & \multirow{2}{*}{$\frac{\text { Mean }}{24}$} & \multirow{2}{*}{$\begin{array}{l}\text { SD } \\
1.7\end{array}$} & \multirow{2}{*}{$\begin{array}{r}\text { Total } \\
201\end{array}$} & \multirow{2}{*}{$\begin{array}{r}\text { Mean } \\
27\end{array}$} & \multirow{2}{*}{$\begin{array}{r}\text { SD } \\
2.3\end{array}$} & \multirow{2}{*}{$\begin{array}{r}\text { Total } \\
201\end{array}$} & & & & & & \\
\hline & & & & & & & \multirow{2}{*}{$\begin{array}{l}9.8 \% \\
9.9 \%\end{array}$} & & & $=$ & & \\
\hline Alguwaihes 2021 [25] & 12.3 & 0.9 & 72 & 10.3 & 0.4 & 150 & & $2.00[1.78,2.22]$ & & & - & \\
\hline Al-Daghri 2021 [26] & 17.8 & 6.6 & 82 & 15.7 & 8.3 & 138 & $7.5 \%$ & $2.10[0.11,4.09]$ & & & $\longrightarrow$ & \\
\hline Baktash 2020 [27] & 14.9 & 3.3 & 35 & 8.7 & 2.2 & 70 & $8.9 \%$ & $6.20[4.99,7.41]$ & & & - & \\
\hline D'Avolio 2020 [28] & 21.9 & 4.3 & 80 & 13.8 & 3.7 & 27 & $8.0 \%$ & $8.10[6.42,9.78]$ & & & 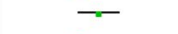 & \\
\hline Hernández 2020 [29] & 20.9 & 7.4 & 197 & 14.4 & 7.4 & 216 & $8.5 \%$ & $6.50[5.07,7.93]$ & & & - & \\
\hline Im 2020 [30] & 25 & 13.2 & 150 & 15.7 & 7.9 & 50 & $5.6 \%$ & $9.30[6.26,12.34]$ & & & & \\
\hline Livingston 2021 [31] & 14.7 & 9.1 & 57 & 11.2 & 8.1 & 47 & $5.2 \%$ & $3.50[0.19,6.81]$ & & & & \\
\hline Mardani 2020 [32] & 30.2 & 9.1 & 60 & 18.5 & 11.6 & 63 & $4.7 \%$ & $11.70[8.02,15.38]$ & & & & \\
\hline Merzon 2020 [33] & 20.6 & 0.1 & 7025 & 19 & 0.2 & 782 & $9.9 \%$ & $1.60[1.59,1.61]$ & & & - & \\
\hline Raisi-Estabragh 2020 [34] & 10.2 & 7.7 & 3184 & 9.8 & 7.8 & 1326 & $9.7 \%$ & $0.40[-0.10,0.90]$ & & & $=$ & \\
\hline Sulli 2021 [35] & 16.3 & 19 & 65 & 7.9 & 15 & 65 & $2.6 \%$ & $8.40[2.52,14.28]$ & & & & \\
\hline Ye 2020 [36] & 20.5 & 1.3 & 80 & 15.8 & 2 & 62 & $9.7 \%$ & $4.70[4.13,5.27]$ & & & $\pi$ & \\
\hline Total $(95 \% \mathrm{Cl})$ & & & 11288 & & & 3197 & $100.0 \%$ & $3.93[2.84,5.02]$ & & & & \\
\hline $\begin{array}{l}\text { Heterogeneity: } \mathrm{Tau}^{2}=3.12 \\
\text { Test for overall effect: } Z=\end{array}$ & $\begin{array}{l}\mathrm{Chi}^{2}= \\
06(\mathrm{P}<\end{array}$ & $\begin{array}{l}85.75 \\
0.000\end{array}$ & $\begin{array}{l}\mathrm{df}=12 \\
\text { 1) }\end{array}$ & $(P<0$. & 0001) & $I^{2}=9$ & & & -20 & $\begin{array}{c}-10 \\
\text { SARS-CoV-2 (-) }\end{array}$ & $\begin{array}{c}10 \\
\text { SARS-CoV-2(+) }\end{array}$ & 20 \\
\hline
\end{tabular}

Figure 2. Forest plot of vitamin D levels between severe acute respiratory syndrome coronavirus 2 (SARS-CoV-2) negative versus positive patients. The center of each square represents the weighted odds ratios for individual trials, and the corresponding horizontal line stands for a 95\% confidence interval (CI). The diamonds represent pooled results; SD - standard deviation.

\begin{tabular}{|c|c|c|c|c|c|c|c|c|}
\hline \multirow[t]{2}{*}{ Study } & \multicolumn{8}{|c|}{ Risk of bias domains } \\
\hline & D1 & D2 & D3 & D4 & D5 & D6 & D7 & Overall \\
\hline Abdollahi et al. 2020 & & & & & & ( & 6 & $\ominus$ \\
\hline Al-Daghiri et al. 2021 & & & & & $\ominus$ & $€$ & $\theta$ & $\ominus$ \\
\hline Alguwaihes et al. 2021 & & - & & $\ominus$ & $\ominus$ & e & - & $\theta$ \\
\hline Baktash et al. 2020 & & & & & & & & - \\
\hline D'Avolio et al. 2020 & & & & & & $€$ & e & $\Theta$ \\
\hline Hernandez et al. 2020 & & & e & & $\ominus$ & e & & $\ominus$ \\
\hline $\operatorname{Im}$ et al. 2020 & ( & - & & & ( & $€$ & $\ominus$ & $\theta$ \\
\hline Livingston et al. 2021 & & & $(-$ & & & - & - & \\
\hline Mardani et al. 2020 & & G & & & & & & \\
\hline Marzon et al. 2020 & & & & & & & ( & $\ominus$ \\
\hline Raisi-Estabragh et al. 2020 & $\ominus$ & & & & & e & $\ominus$ & $\ominus$ \\
\hline Sulli et al. 2021 & & & & & & & & \\
\hline Ye et al. 2020 & & & & & & & 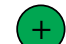 & \\
\hline
\end{tabular}

Figure 3. A summary table of review authors' judgements for each risk of bias item for each study. Domains: D1 - bias due to confouding; D2 - bias due to selection of participats; D3 - bias in classification of interventions; D4 - bias due to deviations from intended interventions; D5 - bias due to missing data; D6 — bias in measurement of outcomes; D7 - bias in selection of the reported result. Judgement: $\circledast$ Serious; $\ominus$ Moderate; $\odot$ Low; (?) No information. 


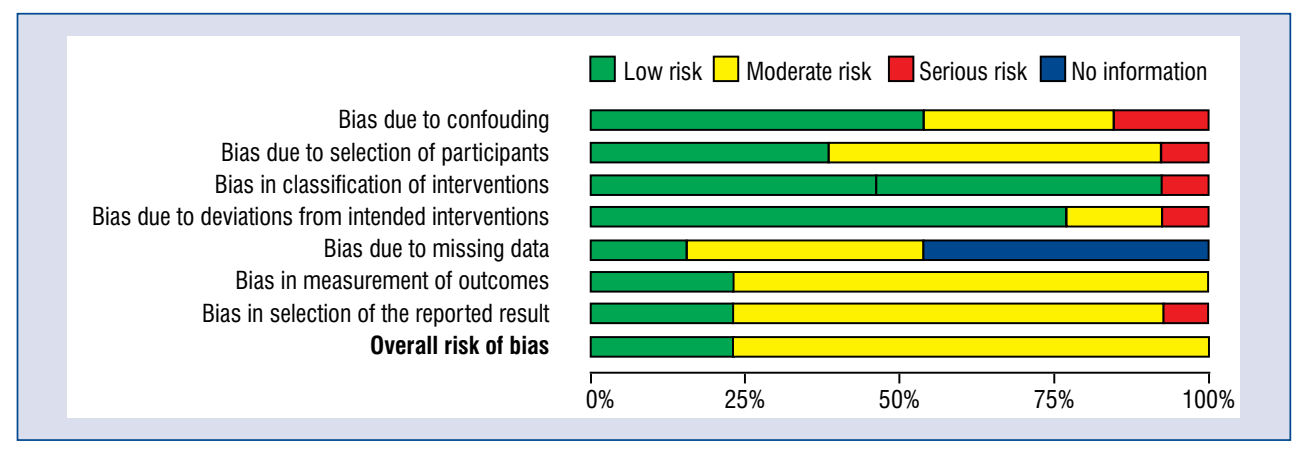

Figure 4. A plot of the distribution of review authors' judgements across studies for each risk of bias item.

obese are also more likely to suffer from vitamin $\mathrm{D}$ deficiency [41]. Another group that suffers from the vitamin D deficiency are older patients [42] both due to the worse overall state of health and due to drugs, they take. The study by Baktash et al. [27] found that the patients who are older than 65 years and present with the COVID-19 symptoms are more likely to be vitamin $\mathrm{D}$ deficient, have elevated markers of cytokine release syndrome and have an increased risk of respiratory failure. However, no difference was found in terms of mortality between the patients who were deficient and those who had their vitamin $\mathrm{D}$ within normal ranges, indicating that in the older group the overall poor prognosis is associated with the general health status and presence of comorbidities. These findings are consistent with those achieved by D'Avolio et al. [28], who also found that vitamin D was lower in the patients positive for COVID-19, while indicating that the supplementation of vitamin D might be useful for prevention of infection.

The strategy of vitamin D supplementation as indicated by Grant et al. [43] suggests the rapid increase of vitamin $\mathrm{D}$ serum levels through the high supplementation for a few weeks going as high as $10,000 \mathrm{IU} /$ day in order to achieve the normal range. This strategy has been used for considearable time and has proven to be safe in delaying frailty [44]. In the study by Al-Daghri et al. [26] vitamin D deficiency was only observed in the group of older patients, those with type 2 diabetes and lower density lipoprotein levels. Interestingly the author, contrary to Grant et al. [43] supports the idea of rather moderate vitamin $\mathrm{D}$ loading in deficient patients, not exceeding $2000 \mathrm{iu} /$ day, which is supported by Bergman [45]. Alguwaihes et al. [25] provides interesting data regarding vitamin D deficiency and the risk of COVID-19 in a hospital setting. While he did not find any evidence suggesting that the risk of infection increases in deficient patients, they are, in fact, at higher risk of mortality, possibly through an unregulated inflammatory response and cytokine storm [46]. Contrary to these findings Hernandez et al. [29] found no difference in the severity of the disease when accounting for vitamin D deficiency, however he did find a higher prevalence of deficiency among hospitalized COVID-19 patients. When analyzing the nutritional status of patients suffering from COVID-19, Im et al. [30] they found that patients suffering from COVID-19 presented a higher percentage of vitamin D deficiency when compared with a control group, additionally while not statistically significant 30 out of 38 patients who suffered from respiratory distress were deficient in vitamin $\mathrm{D}$. What is worth noting is that the patients who required mechanical ventilation were deficient in at least one nutrient. Therefore, it is advised to monitor and react to the nutritional status of the COVID-19 patients [47]. Mardani et al. [32], in his study, analyzed an association in the level of vitamin $\mathrm{D}$ and the severity of COVID-19, along with levels of ACE2 and neutrophil to lymphocyte ratio (NLR). The NLR is a useful tool to assess systemic inflammation [48] also in acute lung injury and acute respiratory distress syndrome [49] which are common findings in the severe course of COVID-19. Having found lower levels of vitamin D in COVID-19 patients, the authors concluded that the deficiency may cause an immunological imbalance, overactivation of the RAS pathway and therefore a hyperinflammation state. Raisi-Estabragh et al. [34] in her study found that vitamin $\mathrm{D}$ deficiency was not an independent risk factor for black, Asian and minority ethnicities and that a cascade of factors play a role rather than a single one that can be pinpointed. In a study by Ye et al. [36], he found that vitamin D deficiency increases risk of COVID-19 infection, while the supplementation of it provides protective effects against 
a severe course of the disease. These findings are further reinforced by Sulli et al. [35] who found that vitamin $\mathrm{D}$ deficiency is associated with more severe lung involvement, longer disease duration, and risk of death in elderly COVID-19 patients. A study by Livingstone et al. [31] among vitamin D deficiency indicates that social deprivation plays role in COVID-19 infection. While studies for the general population showed that social distancing is beneficial for the reduction in COVID-19 incidence rate [50], we must differentiate between social distancing and deprivation since the latter is a well-established risk factor for worsening of health outcomes [51]. Merzon et al. [33] identified vitamin $\mathrm{D}$ deficiency as an independent risk factor not only for COVID-19 infection, but also hospitalization, other risk factors included were being male and over the age of 50 .

All of the studies measured levels of vitamin D at the moment of acute COVID-19 infection, however as previous studies showed [52], acute respiratory infection does not alter the vitamin D levels, therefore a sample on admission is representative.

\section{Conclusions}

Low serum vitamin D levels are statistically and significantly associated with the risk of COVID-19 infection. Supplementation of vitamin D especially in deficiency, risk groups are indicated.

\section{Acknowledgments}

The study was supported by the ERC Research Net and by the Polish Society of Disaster Medicine.

\section{Conflict of interest: None declared}

\section{References}

1. Song F, Shi N, Shan F, et al. Emerging 2019 Novel Coronavirus (2019-nCoV) Pneumonia. Radiology. 2020; 295(1): 210-217. Erratum in: Radiology. 2020 Dec;297(3):E346., doi: 10.1148/ radiol.2020200274, indexed in Pubmed: 32027573.

2. Dzieciatkowski T, Szarpak L, Filipiak KJ, et al. COVID-19 challenge for modern medicine. Cardiol J. 2020; 27(2): 175-183, doi: 10.5603/CJ.a2020.0055, indexed in Pubmed: 32286679.

3. Di Fusco M, Shea KM, Lin J, et al. Health outcomes and economic burden of hospitalized COVID-19 patients in the United States. J Med Econ. 2021; 24(1): 308-317, doi: 10.1080/13696998.2021.1886109, indexed in Pubmed: 33555956.

4. Hamming I, Timens W, Bulthuis MLC, et al. Tissue distribution of ACE2 protein, the functional receptor for SARS coronavirus. A first step in understanding SARS pathogenesis. J Pathol. 2004; 203(2): 631-637, doi: 10.1002/path.1570, indexed in Pubmed: 15141377.
5. Sungnak W, Huang Ni, Bécavin C, et al. SARS-CoV-2 entry factors are highly expressed in nasal epithelial cells together with innate immune genes. Nat Med. 2020; 26(5): 681-687, doi: 10.1038/s41591-020-0868-6, indexed in Pubmed: 32327758.

6. Liu J, Cao R, Xu M, et al. Hydroxychloroquine, a less toxic derivative of chloroquine, is effective in inhibiting SARS-CoV-2 infection in vitro. Cell Discovery. 2020; 6(1), doi: 10.1038/s41421020-0156-0.

7. Sahraei Z, Shabani M, Shokouhi S, et al. Aminoquinolines against coronavirus disease 2019 (COVID-19): chloroquine or hydroxychloroquine. Int J Antimicrob Agents. 2020; 55(4): 105945, doi: 10.1016/j.jiantimicag.2020.105945, indexed in Pubmed: 32194152.

8. Wu D, Yang XO. TH17 responses in cytokine storm of COVID-19: An emerging target of JAK2 inhibitor Fedratinib. J Microbiol Immunol Infect. 2020; 53(3): 368-370, doi: 10.1016/j. jmii.2020.03.005, indexed in Pubmed: 32205092.

9. Szarpak Ł, Dzieciątkowski T, Jaguszewski MJ, et al. Is remdesivir important in clinical practice as a treatment of COVID-19? A study based on meta-analysis data. Pol Arch Intern Med. 2021; 131(1): 96-97, doi: 10.20452/pamw.15686, indexed in Pubmed: 33231938.

10. Polack FP, Thomas SJ, Kitchin N, et al. Safety and Efficacy of the BNT162b2 mRNA Covid-19 Vaccine. N Engl J Med. 2020; 383(27): 2603-2615, doi: 10.1056/NEJMoa2034577, indexed in Pubmed: 33301246.

11. Baden LR, El Sahly HM, Essink B, et al. Efficacy and Safety of the mRNA-1273 SARS-CoV-2 Vaccine. N Engl J Med. 2021; 384(5): 403-416, doi: 10.1056/NEJMoa2035389, indexed in Pubmed: 33378609 .

12. Ho JSY, Fernando DI, Chan MY, et al. Obesity in COVID-19: a systematic review and meta-analysis. Ann Acad Med Singap. 2020; 49(12): 996-1008, indexed in Pubmed: 33463658.

13. Abdi A, Jalilian M, Sarbarzeh PA, et al. Diabetes and COVID-19: a systematic review on the current evidences. Diabetes Res Clin Pract. 2020; 166: 108347, doi: 10.1016/j.diabres.2020.108347, indexed in Pubmed: 32711003.

14. Hu L, Chen S, Fu Y, et al. Risk factors associated with clinical outcomes in 323 coronavirus disease 2019 (COVID-19) hospitalized patients in Wuhan, China. Clin Infect Dis. 2020; 71(16): 20892098, doi: 10.1093/cid/ciaa539, indexed in Pubmed: 32361738.

15. Palacios C, Gonzalez L. Is vitamin D deficiency a major global public health problem? J Steroid Biochem Mol Biol. 2014; 144 Pt A: 138-145, doi: 10.1016/j.jsbmb.2013.11.003, indexed in Pubmed: 24239505 .

16. Wacker M, Holick MF. Vitamin D: effects on skeletal and extraskeletal health and the need for supplementation. Nutrients. 2013; 5(1): 111-148, doi: 10.3390/nu5010111, indexed in Pubmed: 23306192 .

17. Hewison M, Freeman L, Hughes SV, et al. Differential regulation of vitamin D receptor and its ligand in human monocyte-derived dendritic cells. J Immunol. 2003; 170(11): 5382-5390, doi: 10.4049/jimmunol.170.11.5382, indexed in Pubmed: 12759412.

18. Xu H, Soruri A, Gieseler RK, et al. 1,25-Dihydroxyvitamin D3 exerts opposing effects to IL-4 on MHC class-II antigen expression, accessory activity, and phagocytosis of human monocytes. Scand J Immunol. 1993; 38(6): 535-540, doi: 10.1111/j.13653083.1993.tb03237.․․, indexed in Pubmed: 8256111.

19. Moher D, Liberati A, Tetzlaff J, et al. Preferred reporting items for systematic reviews and meta-analyses: the PRISMA statement. PLoS Medicine. 2009; 6(7): e1000097, doi: 10.1371/journal.pmed.1000097. 
20. Sterne JA, Hernán MA, Reeves BC, et al. ROBINS-I: a tool for assessing risk of bias in non-randomised studies of interventions. BMJ. 2016; 355: i4919, doi: 10.1136/bmj.i4919, indexed in Pubmed: 27733354.

21. McGuinness LA, Higgins JPT. Risk-of-bias VISualization (robvis): An $\mathrm{R}$ package and Shiny web app for visualizing risk-ofbias assessments. Res Synth Methods. 2021; 12(1): 55-61, doi: 10.1002/jrsm.1411, indexed in Pubmed: 32336025.

22. Hozo SP, Djulbegovic B, Hozo I. Estimating the mean and variance from the median, range, and the size of a sample. BMC Med Res Methodol. 2005; 5: 13, doi: 10.1186/1471-2288-5-13, indexed in Pubmed: 15840177.

23. Higgins JPT, Thompson SG, Deeks JJ, et al. Measuring inconsistency in meta-analyses. BMJ. 2003; 327(7414): 557-560, doi: 10.1136/bmj.327.7414.557, indexed in Pubmed: 12958120.

24. Abdollahi A, Kamali Sarvestani H, Rafat Z, et al. The association between the level of serum $25(\mathrm{OH})$ vitamin $\mathrm{D}$, obesity, and underlying diseases with the risk of developing COVID-19 infection: A case-control study of hospitalized patients in Tehran, Iran. J Med Virol. 2021; 93(4): 2359-2364, doi: 10.1002/jmv.26726, indexed in Pubmed: 33314166.

25. Alguwaihes A, Sabico S, Hasanato R, et al. Severe vitamin D deficiency is not related to SARS-CoV-2 infection but may increase mortality risk in hospitalized adults: a retrospective case-control study in an Arab Gulf country. Aging Clin Exp Res. 2021; 33(5): 1415-1422, doi: 10.1007/s40520-021-01831-0.

26. Al-Daghri NM, Amer OE, Alotaibi NH, et al. Vitamin D status of Arab Gulf residents screened for SARS-CoV-2 and its association with COVID-19 infection: a multi-centre case-control study. J Transl Med. 2021; 19(1): 166, doi: 10.1186/s12967-021-02838-x, indexed in Pubmed: 33902635.

27. Baktash V, Hosack T, Patel N, et al. Vitamin D status and outcomes for hospitalised older patients with COVID-19. Postgrad Med J. 2021; 97(1149): 442-447, doi: 10.1136/postgradmedj-2020-138712, indexed in Pubmed: 32855214.

28. D'Avolio A, Avataneo V, Manca A, et al. 25-Hydroxyvitamin D concentrations are lower in patients with positive PCR for SARS-CoV-2. Nutrients. 2020; 12(5), doi: 10.3390/nu12051359, indexed in Pubmed: 32397511.

29. Hernández JL, Nan D, Fernandez-Ayala M, et al. Vitamin D Status in Hospitalized Patients with SARS-CoV-2 Infection. J Clin Endocrinol Metab. 2021; 106(3): e1343-e1353, doi: 10.1210/clinem/dgaa733, indexed in Pubmed: 33159440.

30. Im JH, Je YS, Baek J, et al. Nutritional status of patients with COVID-19. Int J Infect Dis. 2020; 100: 390-393, doi: 10.1016/j. ijid.2020.08.018, indexed in Pubmed: 32795605.

31. Livingston M, Plant A, Dunmore S, et al. Detectable respiratory SARS-CoV-2 RNA is associated with low vitamin D levels and high social deprivation. Int J Clin Pract. 2021 [Epub ahead of print]: e14166, doi: 10.1111/ijcp.14166, indexed in Pubmed: 33797849 .

32. Mardani R, Alamdary A, Mousavi Nasab SD, et al. Association of vitamin $\mathrm{D}$ with the modulation of the disease severity in COVID-19. Virus Res. 2020; 289: 198148, doi: 10.1016/j.virusres.2020.198148, indexed in Pubmed: 32866536.

33. Merzon E, Tworowski D, Gorohovski A, et al. Low plasma $25(\mathrm{OH})$ vitamin $\mathrm{D}$ level is associated with increased risk of COVID-19 infection: an Israeli population-based study. FEBS J. 2020; 287(17): 3693-3702, doi: 10.1111/febs.15495, indexed in Pubmed: 32700398

34. Raisi-Estabragh Z, McCracken C, Bethell MS, et al. Greater risk of severe COVID-19 in Black, Asian and Minority Ethnic populations is not explained by cardiometabolic, socioeconomic or behavioural factors, or by $25(\mathrm{OH})$-vitamin D status: study of 1326 cases from the UK Biobank. J Public Health (Oxf). 2020; 42(3): 451-460, doi: 10.1093/pubmed/fdaa095, indexed in Pubmed: 32556213 .
35. Sulli A, Gotelli E, Casabella A, et al. Vitamin d and lung outcomes in elderly COVID-19 patients. Nutrients. 2021; 13(3), doi: 10.3390/nu13030717, indexed in Pubmed: 33668240.

36. Ye K, Tang F, Liao X, et al. Does serum vitamin D level affect COVID-19 infection and its severity? A case-control study. J Am Coll Nutr. 2020 [Epub ahead of print]: 1-8, doi: 10.1080/07315724.2020.1826005, indexed in Pubmed: 33048028.

37. Mitchell F. Vitamin-D and COVID-19: do deficient risk a poorer outcome? Lancet Diabetes Endocrinol. 2020; 8(7): 570, doi: 10.1016/S2213 -8587(20)30183-2.

38. Mok C, Ng Y, Ahidjo B, et al. Calcitriol, the active form of vitamin $\mathrm{D}$, is a promising candidate for COVID-19 prophylaxis. bioRxiv. 2020, doi: 10.1101/2020.06.21.162396.

39. Martineau AR, Forouhi NG. Vitamin D for COVID-19: a case to answer? Lancet Diabetes Endocrinol. 2020; 8(9): 735-736, doi: 10.1016/S2213-8587(20)30268-0, indexed in Pubmed: 32758429.

40. Petrakis D, Margină D, Tsarouhas K, et al. Obesity: a risk factor for increased COVID19 prevalence, severity and lethality (review). Mol Med Rep. 2020; 22(1): 9-19, doi: 10.3892/ mmr.2020.11127, indexed in Pubmed: 32377709.

41. Vranić L, Mikolašević I, Milić S. Vitamin D deficiency: consequence or cause of obesity? Medicina (Kaunas). 2019; 55(9), doi: 10.3390/medicina55090541, indexed in Pubmed: 31466220.

42. Kweder H, Eidi H. Vitamin D deficiency in elderly: Risk factors and drugs impact on vitamin D status. Avicenna J Med. 2018; 8(4): 139-146, doi: 10.4103/ajm.AJM_20_18, indexed in Pubmed: 30319955 .

43. Grant WB, Lahore H, McDonnell SL, et al. Evidence that vitamin D supplementation could reduce risk of influenza and COVID-19 infections and deaths. Nutrients. 2020; 12(4), doi: 10.3390/nu12040988, indexed in Pubmed: 32252338.

44. Bacon CJ, Gamble GD, Horne AM, et al. High-dose oral vitamin D3 supplementation in the elderly. Osteoporos Int. 2009; 20(8) 1407-1415, doi: 10.1007/s00198-008-0814-9, indexed in Pubmed: 19101755 .

45. Bergman P. The link between vitamin D and COVID-19: distinguishing facts from fiction. J Intern Med. 2021; 289(1): 131-133, doi: 10.1111/joim.13158, indexed in Pubmed: 32652766.

46. Daneshkhah A, Agrawal V, Eshein A, et al. Evidence for possible association of vitamin D status with cytokine storm and unregulated inflammation in COVID-19 patients. Aging Clin Exp Res. 2020; 32(10): 2141-2158, doi: 10.1007/s40520-020-01677-y, indexed in Pubmed: 32876941.

47. Mehta S. Nutritional status and COVID-19: an opportunity for lasting change? Clin Med (Lond). 2020; 20(3): 270-273, doi: 10.7861/clinmed.2020-0187, indexed in Pubmed: 32341077.

48. Martins EC, Silveira Ld, Viegas K, et al. Neutrophil-lymphocyte ratio in the early diagnosis of sepsis in an intensive care unit: a case-control study. Rev Bras Ter Intensiva. 2019; 31(1): 64-70, doi: 10.5935/0103-507X.20190010, indexed in Pubmed: 30916236.

49. Wang Y, Ju M, Chen C, et al. Neutrophil-to-lymphocyte ratio as a prognostic marker in acute respiratory distress syndrome patients: a retrospective study. J Thorac Dis. 2018; 10(1): 273-282, doi: 10.21037/jtd.2017.12.131, indexed in Pubmed: 29600057.

50. VoPham T, Weaver MD, Hart JE, et al. Effect of social distancing on COVID-19 incidence and mortality in the US. medRxiv. 2020, doi: 10.1101/2020.06.10.20127589, indexed in Pubmed: 32587998.

51. Charlton J, Rudisill C, Bhattarai N, et al. Impact of deprivation on occurrence, outcomes and health care costs of people with multiple morbidity. J Health Serv Res Policy. 2013; 18(4): 215-223, doi: 10.1177/1355819613493772, indexed in Pubmed: 23945679.

52. Haugen J, Chandyo RK, Ulak M, et al. 25-hydroxy-vitamin D concentration is not affected by severe or non-severe pneumonia, or inflammation, in young children. Nutrients. 2017; 9(1), doi: 10.3390/nu9010052, indexed in Pubmed: 28106720. 